\title{
Are we teleologically essentialist?
}

\author{
Sehrang Joo and Sami R. Yousif
}

Version: October 2021

\begin{abstract}
People may conceptualize certain categories as held together by a category-specific 'essence'- some unobservable, critical feature that causes the external features of a category to emerge. Yet there remains an open question about what comprises this essence. Recently, Rose and Nichols have argued that this essence is comprised of tele, or purposes, (and, in turn, that teleology is the internal force that gives rise to external features). However, Neufeld has challenged this work on theoretical grounds, arguing that these effects arise only because people infer an underlying internal change when reasoning about a change in telos. On Neufeld's view, it is the underlying internal cause, and not the telos itself, that serves as an essence (consistent with classic views of scientific essentialism). Here, we ask: Is teleology the primary force behind psychological essentialism? We begin by successfully replicating Rose and Nichols' key findings in support of teleological essentialism. In two further experiments, however, we demonstrate that teleology may not the central way that people understand the essences of living things: Internal changes matter at least as much as changes to teleology. These findings suggest that while teleology may be one important cue to category membership and the essences of living things, it may be premature to say that we are 'teleologically essentialist.'
\end{abstract}

Keywords: Psychological essentialism; Teleological essentialism; Scientific essentialism; Teleology

\section{Introduction}

What makes a bee a bee, and not a spider? What makes a cup a cup, and not a trophy? People are typically thought to represent categories like 'bee' and 'cup' as held together by a sort of category-specific 'essence'—an 'underlying reality' that gives rise to external features (e.g., Gelmen, 2004; Kelemen \& Carey, 2007). This essence need not be a tangible, identifiable thing; some views posit the existence of a sort of 'placeholder' essence (i.e., people can represent something as having an essence without yet fully specifying what that essence is; Gelman, 2003, 2004). There are many ways to 'fill in' this placeholder. One common way is via scientific essentialism, the view that people think of something's essence as being roughly scientific in nature (e.g., DNA may be the essence of living things; e.g., Gelman, 2003; Gelman \& Heyman, 1999; Gelman \& Markman, 1987; Inagaki \& Hatano, 2002; Newman \& Keil, 2008).

\section{$1.1 \quad$ Teleological Essentialism}

In contrast to this view, Rose and Nichols $(2019,2020)$ propose a more radical idea: the notion of teleological essentialism. According to teleological essentialism, what makes a lion a lion isn't its mane or its roar, or 
even its DNA - but its purpose (e.g., one might think a lion's purpose is to be the 'king of the jungle' or, more concretely, to regulate the population of other animals). The telos of the lion, whatever it may be, is the internal essence which gives rise to its external features. In other words, teleological essentialism shifts the focus away from people's intuitions about animals' scientific nature, and instead recharacterizes psychological essentialism around an understanding of animals' purposes.

Teleological essentialism has the potential to explain a wide range of laypeople's judgments. For instance, teleological essentialism may explain why people say that tea (which they say is 91\% H20) is not water, although a swimming pool (which they say is $82.6 \% \mathrm{H} 20$ ) is water (Malt, 1994) - because the latter serves the function of water, whereas the former does not. Similarly, it may explain why teleological judgments are so widely influential on other sorts of judgments. If people represent something's purpose as its essence, then it makes sense that changing its purpose would change the object's identity (Rose, 2015; Rose, Schaffer, \& Tobia, 2018) or construct a new object (Rose \& Schaffer, 2017). By making teleology central to how we define and represent different objects, teleological essentialism may even help make sense of why teleological explanations are so compelling (Kelemen 1999; Kelemen \& Rosset, 2009).

Teleological essentialism is clearly an intriguing possibility, and it may also be the right way to capture people's essentialist intuitions. Consider, for example, this case from Rose and Nichols (2019):

Some very talented and skilled scientists, Suzy and Andy, decide that they are going to perform a special operation on a bee. They removed its wings and antennae, lengthened its legs, and added a new pair of legs. They also inserted into the back of it something for making webs and trained the animal so that it would eat insects. After running some tests, they found that the thing after the special operation didn't pollinate flowers or make honey. Instead, it only spun webs to catch insects and eat them. (Experiment 1 in Rose $\&$ Nichols, 2019)

In this scenario, people indicate that the bee has become a spider (on a scale from $1=$ it is definitely a bee, to $7=$ it is definitely a spider, the mean score reported is 5.73 ). In a contrasting condition in which the bee's telos is preserved rather than changed, people indicate that the bee remains a bee (on the same scale, the mean score reported is 2.57). This basic phenomenon holds true in several cases, including when the scientists directly change the original bee's features (as shown here), operate on the creature's "insides," or conduct an experiment placing a baby bee in a spiders' cage. Rose and Nichols (2020) extended this finding, showing similar effects not only for animals, but also for artifacts and non-living natural kinds. On the basis of these findings, Rose and Nichols conclude that, "...teleological essentialism is general, [meaning] that essence is represented by a kind of telos for a broad range of categories" (p. 16). 


\subsection{Against Teleological Essentialism}

Recent work, however, challenges teleological essentialism on theoretical grounds. Neufeld (2021) claims that the results observed by Rose \& Nichols $(2019,2020)$ can be explained by a canonical view of scientific essentialism. Specifically, Neufeld argues that people may use information about a change in something's telos as way to infer a change in its underlying scientific essence.

Consider, for instance, this scenario from Hampton, Estes, and Simmons (2007): A bird falls out of the sky into a vat of hazardous chemicals, and it emerges from the chemicals looking more like a spider than a bird. The critical finding here, according to Neufeld, is not that people view the creature after its transformation as a spider, but that they do so because of some deeper inference about the insides of the creature. That is, participants reasoned that some internal change must have given rise to the observed physical or behavioral changes, and this inferred internal change was what led them to classify the creature as a spider. Perhaps the animals' DNA was altered, for example - in which case scientific essentialism should predict a change in category membership. In other words, on this view, only the internal (or scientific) essence is a true cause of the animals' external features, and so people infer that any change in such features is the result of a change in essence (see also Rehder \& Hastie, 2001). This is consistent with classic work (Keil, 1989), in which changes attributed to external causes do not result in changes to category membership, ostensibly because it is clear that no essence has been altered.

Neufeld argues that these inferences are also present in the experiments from Rose and Nichols (2019). After a bee gains the telos of a spider (i.e., it starts spinning webs and catching insects instead of pollinating flowers and making honey), Rose and Nichols find that people think the creature after this change is a spider. On Neufeld's view, the description of the creature's telos after the experiment may still lead to inferences about further, perhaps deeper, internal changes. In other words, when participants are told that the creature spins webs like a spider, they assume that key "insides" have changed to be like those of spider - and when told that the creature continues to pollinate flowers, they assume that these key "insides" are still more like those of a bee. In other words, Rose and Nichols's $(2019,2020)$ vignettes may be ambiguous with respect to the causal nature of the observed teleological changes.

\subsection{Current Study}

The goal of the experiments reported here is to test whether teleological essentialism holds up empirically in a range of scenarios. Our aim is not to prove or disprove teleological essentialism, but to provide stronger test cases of this theory. On the one hand, it is possible that teleological essentialism is robust, and that people do 
in fact categorize objects based on their teleology - over and above any inferences about underlying causes. On the other hand, it is possible that while people's understanding of animals' essences may be affected by teleological information, their intuitions are primarily the result of inferring deeper causal changes.

We begin (Experiments 1a-c) by replicating three key experiments from Rose \& Nichols, (2019). In line with their original results, we show that teleology seems to play some role in essentialism. Next (Experiment 2), we directly contrast teleological changes with changes to deeper 'insides.' We find that people's essentialist intuitions are driven by their understanding of animals 'insides' just as much as by their understanding of animals' tele. Finally (Experiment 3), we contrast teleological changes with insides changes in separate scenarios. We present participants with simplified vignettes in an effort to minimize the extent to which they may infer any additional changes, and find that (at least in some cases) information about 'insides' changing matters more to people's essence judgments than information about teleology. Across these experiments, we have opted to focus on the canonical example of a bee-turned-spider because this example speaks most meaningfully to the broader debate on essentialism (see Neufeld, 2021). That is, for artifacts, unlike animals, category membership based on functions makes more sense as a general principle, and does not pose any challenge to the view of scientific essentialism more broadly.

\section{Experiments 1a-c: Direct Replications}

Here, we aim to replicate Experiments 1-3 from Rose \& Nichols (2019). We contrast cases where a creature's telos changed with cases where it did not, and ask participants to evaluate "“to what extent [they] think that the thing after the special operation is a bee or spider?"

\subsection{Method: Experiment 1a}

\subsubsection{Participants}

One hundred adult participants completed a survey online through Amazon Mechanical Turk, recruited through CloudResearch. The sample size was preregistered. All participants lived in the United States. Data from an additional 25 participants was collected but excluded for failing one or more comprehension checks (see Procedure section).

\subsubsection{Procedure}

Participants were given the following scenario:

Some very talented and skilled scientists, Suzy and Andy, decide that they are going to perform a 
special operation on a bee. They removed its wings and antennae, lengthened its legs and added a new pair of legs. They also inserted into the back of it something for making webs and trained the animal so that it would eat insects.

On the same page, they were then shown two images, from before and after the special operation (the 'before' image looked like a bee and the 'after' image looked like a spider) Participants were then told that the creature either changed or preserved its telos, or purpose, after the operation:

[Telos changed] After running some tests, they found that the thing after the special operation didn't pollinate flowers or make honey. Instead, it only spun webs to catch insects and eat them.

[Telos preserved] After running some tests, they found that the thing after the special operation didn't spin webs to catch insects and eat them. Instead, it only pollinated flowers and made honey.

Participants were asked two true/false comprehension questions. They were asked to evaluate a statement about the events of scenario (e.g., "Suzy and Andy performed a special operation on a bee") and a statement about the teleology manipulation (e.g., "The thing after the special operation only spins webs to catch insects and eat them.") These comprehension questions, as well as all other details of the vignette, were exactly the same as those used in Rose \& Nichols (2019) Experiment 1.

Participants were then asked "To what extent do you think that the thing after the special operation is a bee or a spider?" on a 1-7 scale, where 1 was "It is definitely a bee" and 7 was "It is definitely a spider."

Data, materials, and preregistration information for this experiment and all following can be found on the Open Science Framework (OSF) at https://osf.io/x5gf6/?view_only=9d26eccf085240b283f737d03b6b760b.

\subsection{Results: Experiment 1a}

Results from Experiments 1a-c are shown in Figure 1. Participants' categorization of the creature after its transformation depended on whether or not its telos had changed, $t(98)=7.93, p<.001$. Specifically, when the creature's telos changed to that of a spider, participants thought it was a spider, $M=5.46, S D=1.69$, $t(49)=6.10, p<.001$, and when the creatures' telos was still that of a bee, participants thought it was a bee, $M=2.72, S D=1.76, t(49)=5.14, p<.001$.

\subsection{Method: Experiment 1b}

All elements of the experimental design were identical to those of Experiment 1a, except as stated below. One hundred new participants completed the survey online through Amazon Mechanical Turk. This sample size was chosen to be identical to that in the previous experiment. Data from an additional 10 participants were excluded for failing one or more comprehension checks. 


\section{Results from Exp. 1a-c: Replicating Teleological Essentialism}

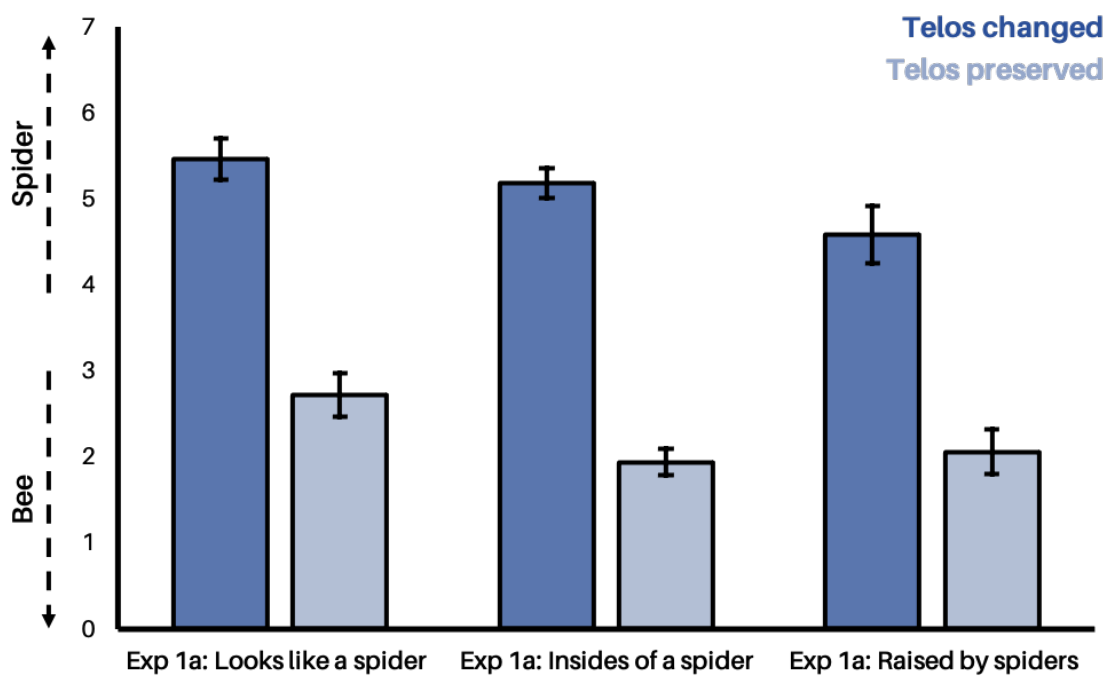

Figure 1: Results of Experiments 1a-c, replicating Experiments 1-3 in Rose \& Nichols, 2019. In all experiments, participants thought the creature after its transformation was more like a spider when its telos changed than when it did not. In Experiment 1a, the creature ended up looking like a spider. In Experiment 1b, the creature's insides changed. In Experiment 1c, it grew up in a cage full of spiders. Error bars represent $+/-1$ standard error.

Participants were now presented with the vignette from Rose and Nichols (2019) Experiment 2:

Some very talented and skilled scientists, Suzy and Andy, decide that they are going to perform a special operation on a bee. They decide to remove the insides of the bee and replace them with the insides from a spider.

They were shown the same image (of a bee, see Figure 1) twice: once to represent the creature before the operation and once to represent it after the operation.

\subsection{Results: Experiment 1b}

Participants' categorization of the creature after its transformation depended on whether or not its telos had changed, $t(98)=13.84, p<.001$. Specifically, when the creature's telos changed to that of a spider, participants thought it was a spider, $M=5.18, S D=1.24, t(49)=6.73, p<.001$, and when the creatures' telos was still that of a bee, participants thought it was a bee, $M=1.94, S D=1.10, t(49)=13.30, p<.001$.

\subsection{Method: Experiment 1c}

All elements of the experimental design were identical to those of previous experiments, except as stated below. One hundred new participants completed the survey online through Amazon Mechanical Turk. This 
sample size was chosen to be identical to that in the previous experiment. Data from an additional 7 participants were excluded for failing one or more comprehension checks.

Participants were now presented with the vignette from Rose and Nichols (2019) Experiment 3: Some very talented and skilled scientists, Suzy and Andy, decide that they are going to perform a special experiment with a newborn bee. After an egg hatches, they place the newborn bee in a cage full of spiders.

No images were shown because no images were shown in the original experiment.

\subsection{Results: Experiment 1c}

Participants' categorization of the creature after its transformation depended on whether or not its telos had changed, $t(98)=6.04, p<.001$. Specifically, when the creature's telos changed to that of a spider, participants thought it was a spider, $M=4.58, S D=2.33, t(49)=3.23, p<.001$, and when the creatures' telos was still that of a bee, participants thought it was a bee, $M=2.06, S D=1.81, t(49)=5.62, p<.001$.

\subsection{Discussion: Experiments 1a-1c}

Here, we replicate the key findings of Rose and Nichols (2019). Consistent with teleological essentialism, people's classifications of the creature after its transformation were affected by whether or not its telos had changed.

\section{Experiment 2: Are people uniquely teleologically essentialist?}

The previous experiments are consistent with a view that people are teleologically essentialist. However, a strong view of teleological essentialism would predict not only that people's category judgments are affected by the creature's telos, but also that their judgments are affected only or at least primarily by the creature's telos. Here, we test this prediction directly. We contrast cases where a bee's telos did/did not change with cases where its 'insides' (i.e., its organs and DNA) did/did not change to be like a spider's, and ask participants how best to classify the creature after its transformation: as a bee, a spider, or neither.

\subsection{Method}

\subsubsection{Participants}

Four hundred new participants completed the survey online, recruited directly from Amazon Mechanical Turk. This sample size was chosen to double the number of participants per condition (since unlike the 
previous experiments, this experiment was not a direct replication). The sample size was preregistered. All participants lived in the United States. Data from an additional 45 participants was collected but excluded for failing one or more comprehension checks (see Procedure section).

\subsubsection{Procedure}

In a 2 (Telos: changed / stayed the same) x 2 (Insides: changed / stayed the same) between-subjects design, participants were randomly assigned to one vignette. Language in the vignettes was adapted from Rose \& Nichols (2019) with minimal changes. Participants in all conditions were shown the following set up:

Some very talented and skilled scientists, Suzy and Andy, decide that they are going to perform a special experiment on a bee.

This was followed about information about whether the bee's telos changed and about whether its insides changed.

Before the special experiment, the bee pollinated flowers and made honey.

[Telos Changed] After the special experiment, it no longer pollinated flowers and made honey. Instead, it spun webs to catch insects and eat them. In fact, Suzy and Andy found that it only ever acted like a typical spider.

[Telos Same] After the special experiment, it still pollinated flowers and made honey. And it still didn't spin webs to catch insects and eat them. Before the special experiment, the bee pollinated flowers and made honey. In fact, Suzy and Andy found that it only ever acted like a typical bee.

[Insides Changed] Afterwards, Suzy and Andy also found that the creature's insides seemed completely different - all the organs and even the DNA itself were now much more like those of a spider than those of a bee. In fact, Suzy and Andy could not find any discernible differences between the creature's insides and the insides of a typical spider.

[Insides Same] Afterwards, Suzy and Andy also found that the creature's insides seemed like they hadn't changed at all - all the organs and even the DNA itself were still much more like those of a bee than those of a spider. In fact, Suzy and Andy could not find any discernible differences between the creature's insides and the insides of a typical bee.

Participants were always shown information about the creature's telos first, followed by information about its insides.

Participants were then asked a forced-choice question about the best way to classify the creature after the special experiment: as a bee, a spider, or neither. We chose this discrete measure in order to give participants clear options, rather than rely on their interpretations of a scale.

Finally, participants were asked two true/false comprehension questions. One question, about whether 
or not the creature's telos changed (i.e., "The thing after the special experiment only spins webs to catch and eat them"), was taken directly from Rose \& Nichols' procedure. The second question was the analogous check of participants' understanding of whether or not the creature's insides changed (i.e., "The creature after the special experiment has organs that seem more like a spider's than like a bee's").

\section{$3.2 \quad$ Results}

Results from Experiment 2 are shown in Figure 2. Data were analyzed using $\mathrm{R}$ with the nnet package, and were fit to multinomial logistic models. There were significant main effects of both a change in telos, $X^{2}(2, N=200)=124.12, p<.001$, and change in insides, $X^{2}(2, N=200)=160.04, p<.001$. Compared to when neither the creature's telos nor its insides changed $(\hat{p}=.99)$, participants were less likely to classify the creature as a bee when either its telos $(\hat{p}=.66), z=35.46, p<.001$, two-tailed, or its insides changed $(\hat{p}=.55)$, $z=52.2, p<.001$, two-tailed. They were also more likely to classify it as 'neither' (when neither changed: $\mathrm{p}=0)$, when its telos $(\hat{p}=.26), z=27.6, p<.001$, two-tailed, or its insides changed $(\hat{p}=.36), z=42.50, p<.001$, two-tailed. However, while a majority of participants classified the creature as a spider when both its telos and insides changed $(\hat{p}=63, p<.001$, binomial test - a majority of participants classified the creature as a bee when only its telos or its insides $(p \mathbf{s}<.001)$.

There was also a significant interaction between change in telos and change in insides, $X^{2}(2, N=$ $400)=10.46, p=.005$. This interaction was driven by the differences in 'neither' and 'spider' responses across conditions (see above). However, none of participants' categorizations ('bee', 'spider,' and 'neither') were significantly different between the conditions where only the telos or only the insides changed $(p \mathrm{~s}>.15)$.

\subsection{Discussion}

While there was a main effect of telos changes on people's judgments, there was also (an equally large) main effect of changes to the creature's insides. When comparing only the conditions where the creature's insides changed, the results of this experiment conceptually replicate the influence of teleology on animals' essences: As in Experiment 1a-c, people tended to think the creature was a bee when its telos didn't change and to think it was a spider when it did. However, the $2 \times 2$ design in this experiment also demonstrated that the same could be said of changes to the creature's insides: When comparing only the conditions where the creature's telos changed, people tended to think the creature was a bee when its insides didn't change and to think it was a spider when they did. In other words, these results are inconsistent with a strong view of teleological essentialism. People's judgments are clearly not affected only or even primarily by teleological information. 
Exp. 2: Telos vs. Insides Changes

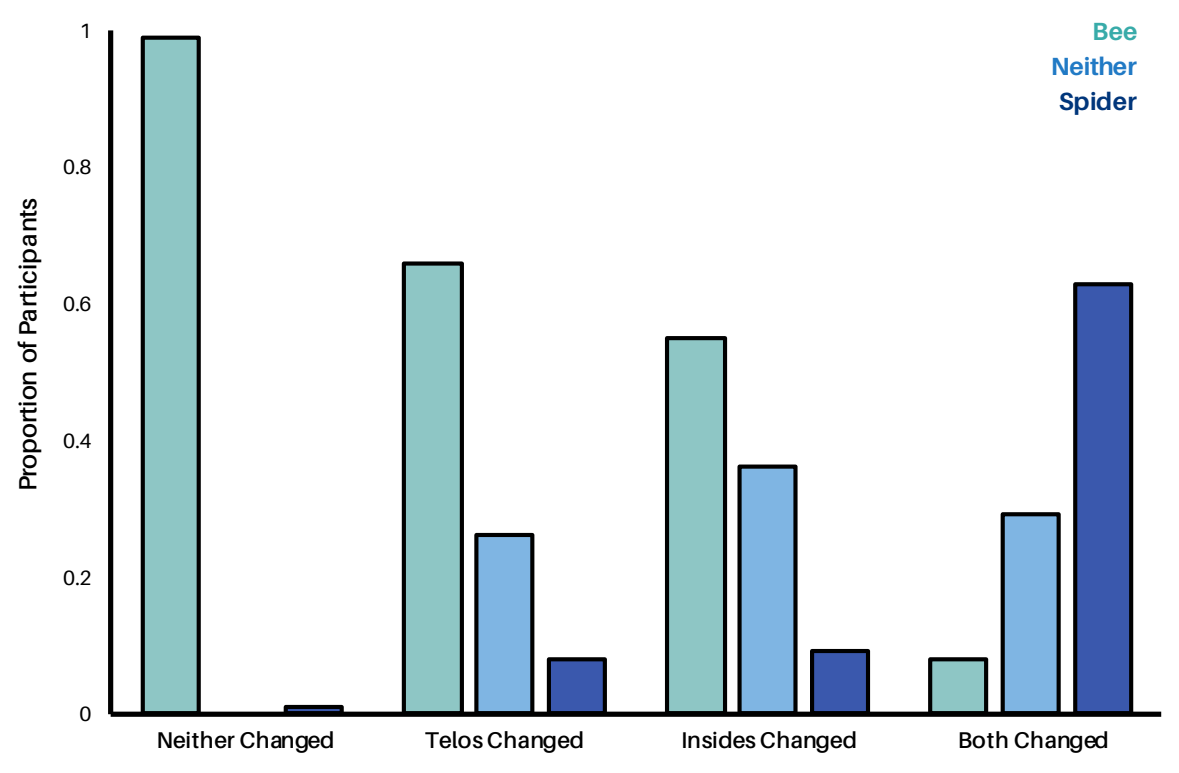

Figure 2: Results from Experiment 2. Participants thought that a bee which changed neither its telos nor insides (i.e., to be like a spider) after an experiment was still a bee. When both the bee's telos and its insides changed, participants tended to think it was a spider. However participants had mixed intuitions when considering cases where only either the creature's telos or its insides changes, and a majority continued to classify it as a bee.

What might this mean for teleological essentialism more generally? On the one hand, it seems that people's judgments are affected to some extent by teleological information. On the other hand, the direct contrast between changes to telos and changes to 'insides' demonstrated the difficulty in pulling these concepts fully apart. Many of our participants directly noted that it seemed unusual or even impossible both for the creature to act like a spider without any discernible changes to its insides, and for it to act like a bee when its insides were indistinguishable from that of a spider (all responses to this free-response question are available in full on our OSF page). It is challenging, in practice, to convince participants that no internal changes occurred when the creature changes to such an extent. Thus, the effects of teleology that we do observe may nevertheless be due to some other inference that participants are making.

\section{Experiment 3: Teleological vs. Scientific Essentialism}

In the previous experiment, people's category judgments were equally influenced by both teleological and internal changes. Here, we (1) seek to conceptually replicate these results in a different paradigm, and (2) ask whether one factor may sometimes carry greater weight than another.

We begin with one of Rose \& Nichols' (2019) vignettes - one in which scientists experiment on a baby 
bee by placing it in a cage full of spiders, and examine cases where either the creature's telos changes (and it spins webs to catch insects) or its insides change (and it has DNA like that of a spider). Here, we make two key changes from Experiment 2. First, participants are only given information about either a telos change or an insides change. Second, we simplify the language of the vignettes by eliminating mention of "scientists" conducting a "special experiment." We remove this language because we think it may directly encourage erroneous inferences. For example, one might think that the scientists made other changes to the creature while setting up their experiment, and in this case teleological changes may appear to have a bigger impact on participants' category judgments than they otherwise would.

\subsection{Method}

\subsubsection{Participants}

Two hundred new participants completed the survey online, recruited directly from Amazon Mechanical Turk. This sample size was chosen to be identical (within each condition) to the number of participants in each condition of the previous experiment. This experiment was also preregistered.

\subsubsection{Participants}

Procedure Participants were randomly assigned to either the telos changed or the insides changed conditions. They were presented with one version of the following scenario:

Suppose that the moment it hatches, a newborn bee is placed in a cage full of spiders.

[Telos Changed] After two weeks, the creature doesn't pollinate flowers or make honey. Instead, it only spins webs to catch them and eat them.

[Insides Changed] After two weeks, the creature doesn't seem to have the insides of a bee. Instead its insides seem completely different - all the organs and even the DNA itself are now much more like those of a spider than those of a bee.

Language for the telos changed condition was adapted from Rose \& Nichols' language of telos change, consistent with prior experiments. Language for the insides changed condition was adapted from that of the previous experiment.

Participants were then asked "Which of the following best describes the animal?" and could choose between "bee," "spider," and "neither." We set up this study in the simplest way possible: no images were included, all information and the question was on a single page, and no further questions were asked. 


\section{Exp. 3: Telos \& Insides Changes in Simple Vignettes}

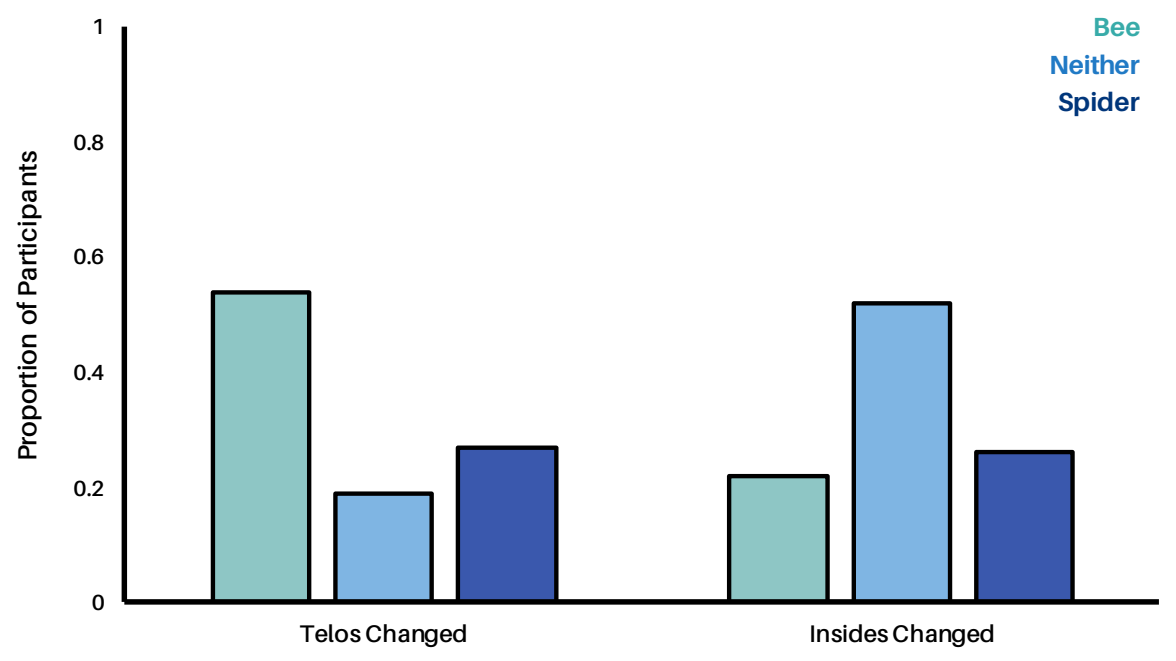

Figure 3: Results from Experiment 3. Participants were shown a simplified version of a scenario in which a baby bee is placed in a cage of spiders. When its telos changed, they tended to think it was a bee. But when its insides changed, they thought the creature had changed enough to be neither a bee nor a spider.

\subsection{Results}

Results from Experiments 3 are shown in Figure 3. In general, participants thought that the creature had changed more when its insides had changed than when its telos had changed. They were less likely to classify the creature as a bee when its insides changed than when its telos changed (telos changed: $\hat{p}=.54$; insides changed: $\hat{p}=.22), z=20.40, p<.001$, two-tailed, and more likely to classify it as now neither a bee nor a spider (telos changed: $\hat{p}=.19$; insides changed: $\hat{p}=.52$ ) $, z=22.36, p<.001$, two-tailed. They were not, however, any more likely to classify it as fully a spider (telos changed: $\hat{p}=.27$; insides changed: $\hat{p}=.26$ ), $p>.05$, two-tailed.

\subsection{Discussion}

In general, participants think that a creature is no longer a bee once its insides have changed to resemble a spider. These results, along with those of Experiment 2, suggest that insides changes have at least as much bearing on essences as teleological changes. Here, in fact, changes to the animals' insides mattered more than teleological changes; when the bee's telos changed, participants still thought it was a bee.

One possibility for why teleological changes did not impact participants' category judgments in this experiment (as opposed to prior experiments) is that we removed all language of "scientists" performing a "special experiment." Such language (present in previous experiments) may lead participants to make further inferences about underlying causes. Take this first sentence of the vignette from Experiment 3b and Rose \& Nichols (2019): 
Some very talented and skilled scientists, Suzy and Andy, decide that they are going to perform a special operation on a bee.

Here, the reader is given several important pieces of information. First, they are told that Suzy and Andy are intentionally performing an operation. Second, they are told that this operation is 'special,' although the meaning of this word is never explained. Third, they are told that Suzy and Andy are experts ("very talented and skilled"), meaning that whatever intention they have to perform an operation is likely not aimless. These seemingly innocuous details of the vignettes meaningfully shape how a reader may interpret the information that follows. Neufeld (2021) argues that people interpret a change in telos as necessarily requiring a change in scientific essence. If so, this may explain why this additional information about scientists performing an experiment influences participants' intuitions about teleological changes: Such information may facilitate further inferences (i.e., about insides) in the case of teleology but not in the case where participants are directly told about changes to the creature's insides.

\section{General Discussion}

What is the best way to characterize psychological essentialism? While we replicate key findings in support of teleological essentialism (Experiments 1a-c), our results ultimately suggest that teleology is not the driving force of psychological essentialism (Experiments 2,3).

\subsection{Scientific vs. Teleological Essentialism}

A strong view of teleological essentialism would require that teleology is the primary way that people understand the essences of living things. In contrast to this view, however, these results offer empirical support for the argument made by Neufeld (2021): People's category judgments may be influenced by teleological information not because they are directly teleologically essentialist, but because they infer that deeper internal changes gave rise to this change in telos. In other words, while something's telos may not itself be an essence, people may use teleological information in order to infer something's scientific essence. This perspective can explain both why people are puzzled about cases where only a creature's telos or only its insides changed (see Experiment 2), and why their intuitions about 'insides' changes appear more stable than their intuitions about telos changes (see Experiments 3a-b). Thus, consistent with the argument made by Neufeld (2021), we find that the effects observed by Rose \& Nichols (2019) may in fact be consistent with standard views of essentialism.

Even if people are 'scientifically essentialist', the idea that something's telos may be a particularly salient 
cue to its internal essence remains quite striking. We know that teleological thinking plays an important role in many other areas of cognition - influencing judgments of category membership (Matan \& Carey, 2001), persistence (Rose, 2014), mereology (Rose \& Schaffer, 2017), and explanation (Kelemen, 1999; Kelemen \& Rosset, 2009). One way to understand this influence is to consider object's purposes as a simple, but particularly useful, cue to many complex properties. For instance, learning that something like a microwave is for heating food can also convey that those pieces of metal make a single object, that heating food is a key characteristic of microwaves generally, and that this microwave exists because it was designed to serve that purpose. Similarly, learning something's telos could convey something about its deeper insides. A change in something's telos may then be a heuristic through which we infer that something's insides have changed sufficiently to change its insides. In other words, even if people are not primarily teleologically essentialist, teleology seems to play some role in how people figure out objects' essences.

Teleological essentialism may also turn out to be the best way to describe the essences of things other than animals. Scientific essentialism is largely restricted to natural kinds (Gelman, 2003; Gelman \& Heyman, 1999; Gelman \& Markman, 1987; Inagaki \& Hatano, 2002; Newman \& Keil, 2008) — but people have also been found to ascribe essences to many other sorts of things, including various social categories (e.g., Haslam et al., 2004; Haslam \& Levy, 2006; Morton et al., 2009; Williams \& Eberhardt, 2008), moral character (Heiphetz, 2019, 2020), and abstract concepts (e.g., Knobe et al., 2013). Recent work also suggests that there may be a general way of understanding essentialism across these cases, even though only some of them seem to be scientific or causal (Newman \& Knobe, 2018). Whether teleology plays some role in these other cases not typically explained by scientific essentialism, or in some more generalized understanding of essence, is an open question.

\subsection{Other (Methodological) Concerns}

Our changes to Rose \& Nichols' vignettes are simple. Yet they have striking effects on people's judgments. These findings thus have methodological implications for not only the study of teleology and of essentialism, but also for related bodies of work (e.g., on categories, kinds, etc.). We discuss three key takeaways.

First, participants respond differently to a continuous vs. discrete response scheme, potentially resulting in findings that may be interpreted quite differently. For instance, the high rate of 'neither' responses that we found with a discrete response scheme may suggest that participants do not necessarily treat the middle range of the scale as a true midpoint. With discrete options, however, it may be that participants could express clearly when they thought the creature had changed too much to still be a bee, but was still not quite a spider. Our point is not that one of these measures is more appropriate in this case or in general, 
but simply to bring attention to this subtle but potentially critical design detail.

Second, extraneous information can affect how participants are understanding the scenario - particularly when this information concerns intentional agents. We suggest that details (such as skilled scientists performing an experiment) do more than simply add context to a vignette. Instead, the presence of such information may meaningfully influence people's interpretation of the manipulation. In some of these experiments, for instance, it may have been that people inferred that the scientists made some internal change to the organism (even though internal changes were never explicitly mentioned in the vignette).

Finally, it may be important to reconsider what it means for something like a bee or a spider to have a telos in the first place. Following Rose \& Nichols (2019, 2020), we treat characteristic behaviors of a bee or a spider as the telos of that kind. We take for granted (as Rose \& Nichols did) that features like pollinating flowers and making honey or spinning webs and catching insects best characterize these animals' tele. Yet animals may not truly have tele at all (consider, for instance, what may be the telos of a hippopotamus, or an octopus, or a beetle). Instead, it may be that the manipulations employed here simply reflect the fact that pollinating flowers and making honey are prototypical features of bees (whether or not those prototypical features constitute tele). If true, it would mean that even if we did observe strong effects in this paradigm, strong claims about teleological essentialism may still be unwarranted. To further this debate, it is vital that we first more clearly define what it means to have a telos in the first place.

Even if animals do have tele, multiple criteria exist in principle for defining this telos. For instance, is an animal's telos the function it may serve for humans (similar to the sense in which the purpose of a hammer is to drive in nails)? Or is it something it does for a larger 'organism,' such as the ecosystem to which it belongs (similar to the sense in which the purpose of a giraffe's neck is to reach tall trees; see also ojalehto et al., 2013?)? Or is it its realizable potential (similar to the sense in which an acorn's purpose is to become an oak tree)? These different approaches may concretely affect how one studies something's telos: Depending on one's view, it may be that the purpose of a spider isn't to spin webs or even to catch insects, but specifically to manage insect populations. Do changes to all of these kinds of tele result in similar influences on category membership? We would think not. Yet the view put forth by Rose and Nichols does not specify when we should or should not expect such effects.

\subsection{Conclusion}

Are people teleologically essentialist? The experiments reported here suggest that teleology may play some part of psychological essentialism-but that psychological essentialism as a whole may not be best charac- 
terized as teleological. Instead, people may reason about objects' purposes in addition to reasoning directly about their insides, at least in part because identifying something's purpose may shed light on its internal parts. While the findings of Rose and Nichols $(2019,2020)$ reveal yet another way that teleological thinking is central to human cognition, they appear to stop short of radically re-characterizing psychological essentialism. 


\section{Acknowledgments}

We thank Joshua Knobe, Frank Keil, and all members of the Yale Cognition and Development Lab for helpful comments and conversation. This project was supported by a National Science Foundation Graduate Research Fellowship awarded to S. R. Yousif. 


\section{References}

Gelman, S. (2003). The essential child. New York: Oxford University Press.

Gelman, S. A. (2004). Psychological essentialism in children. Trends in Cognitive Sciences, 8(9), 404-409.

Gelman, S. A., \& Heyman, G. D. (1999). Carrot-eaters and creature-believers: The effects of lexicalization on children's inferences about social categories. Psychological Science, 10, 489-493.

Gelman, S. A., \& Markman, E. M. (1986). Categories and induction in young children. Cognition, 23, 183-209.

Hampton, J. A., Estes, Z., \& Simmons, S. (2007). Metamorphosis: Essence, appearance, and behavior in the categorization of natural kinds. Memory and Cognition, 35(7), 1785-1800.

Haslam, N., Bastian, B., \& Bissett, M. (2004). Essentialist Beliefs about Personality and Their Implications. Personality and Social Psychology Bulletin, 30(12), 1661-1673.

Haslam, N., \& Levy, S. (2006). Essentialist beliefs about homosexuality: Structure and implications for prejudice. Personality and Social Psychology Bulletin, 32, 471-485.

Heiphetz, L. (2019). Moral essentialism and generosity among children and adults. Journal of Experimental Psychology: General, 148(12), 2077-2090.

Heiphetz, L. (2020). The development and consequences of moral essentialism. Advances in Child Development and Behavior, 59, 165-194.

Inagaki, K., \& Hatano, G. (2002). Young children's naive thinking about the biological world. New York: Psychology Press.

Keil, F. C. (1989). Concepts, kinds, and cognitive development. Cambridge, MA: MIT Press.

Kelemen, D. (1999). Why are rocks pointy? Children's preference for teleological explanations of the natural world. Developmental Psychology, 35, 1440-1452.

Kelemen, D. (2004). Are children "intuitive theists"? Reasoning about purpose and design in nature. Psychological Science, 15(5), 295-301.

Kelemen, D. \& Carey, S. (2007). The essence of artifacts: Developing the design stance. In E. Margolis \& S. Laurence (Eds.), Creations of the mind: Theories of artifacts and their representation (pp.212-230). New York, NY: Oxford University Press. 
Kelemen, D., \& Rosset, E. (2009). The human function compunction: Teleological explanation in adults. Cognition, 111, 138-143.

Kelemen, D., Rottman, J., \& Seston, R. (2013). Professional physical scientists display tenacious teleological tendencies: Purpose-based reasoning as a cognitive default. Journal of Experimental Psychology: General, 142, 1074-1083.

Knobe, J., Prasada, S., \& Newman, G. (2013). Dual character concepts and the normative dimension of conceptual representation. Cognition, 127, 242-257.

Malt, B. C. (1994). Water is not H2O. Cognitive Psychology, 27, 41-70.

Matan, A., \& Carey, S. (2001). Developmental changes within the core of artifact concepts. Cognition, 78, $1-26$.

Morton, T. A., Postmes, T., Haslam, S. A., \& Hornsey, M. J. (2009). Theorizing gender in the face of social change: Is there anything essential about essentialism? Journal of Personality and Social Psychology, $96,653-664$.

Neufeld, E. (2021). Against Teleological Essentialism. Cognitive Science, 45(4), e12961.

Newman, G.E, \& Keil, F.C. (2008). 'Where's the essence?': Developmental shifts in children's beliefs about the nature of essential features. Child Development, 79, 1344-1356.

Newman, G. E., \& Knobe, J. (2019). The essence of essentialism. Mind ES Language, 34 (5), 585- 605.

ojalehto, b., Waxman, S.R., and Douglas L.M. (2013). Teleological Reasoning About Nature: Intentional Design or Relational Perspectives? Trends in Cognitive Sciences, 17, 166-171.

Rehder, B., \& Hastie, R. (2001). Causal knowledge and categories: The effects of causal beliefs on categorization, induction, and similarity. Journal of Experimental Psychology: General, 130(3), 323.

Rose, D. (2014). Persistence through function preservation. Synthese, 192, 97-146.

Rose, D., \& Nichols, S. (2019). Teleological essentialism. Cognitive Science, 43(4), e12725.

Rose, D., \& Nichols, S. (2020). Teleological Essentialism: Generalized. Cognitive Science, $44(3)$, e12818.

Rose, D., \& Schaffer, J. (2017). Folk Mereology is Teleological. Noûs, 51, 238-270.

Rose, D., Schaffer, J., \& Tobia, K. (2018). Folk teleology drives persistence judgments. Synthese, 197(12), 5491-5509. 
Williams, M. J., \& Eberhardt, J. L. (2008). Biological conceptions of race and the motivation to cross racial boundaries. Journal of Personality and Social Psychology, 94, 1033-1047. 